Fothergill, P. G. \& Ashcroft, R. (1955). J. gen. Microbiol. 13, 399-407

\title{
Further Nutritional Studies of Venturia inaequalis
}

\author{
By P. G. FOTHERGILL* \\ Botany Department, King's College, Newcastle upon Tyne 1 \\ AND \\ ROSALIND ASHCROFT
}

Pathology Department, Royal Victoria Infirmary, Nerwastle upon Tyne 1

\begin{abstract}
SUMMARY: A series of nutritional experiments was carried out on cultures from single ascospores isolated from a single ascus of Venturia inaequalis. The results showed: $(a)$ thiamine stimulated all cultures and other vitamins did so to a much less extent; (b) decoctions of apple leaves contained stimulatory substances; $(c)$ these substances were amino acids, chiefly isoleucine, glutamine, serine and phenylalanine; $(d)$ best growth was given by some cultures in the presence of thiamine and various amino acids; $(e)$ the reaction of the fungus cultures to the decoctions, amino acids and thiamine varied according to the cultures and the combination of nutrients. There were indications that the nutritional requirements reflected the genetic composition of a given culture; $(f)$ in the absence of leaf decoctions the best sources of nitrogen were Oxoid peptone and asparagine, and growth with these substances reflected the genetic composition of the organism; $(g)$ at least ten amino acids were shown to be present in the leaves of all or some apple varieties.
\end{abstract}

In a previous paper Fothergill \& Asheroft (1955) showed that a strain of Venturia inaequalis, the cause of apple scab, obtained from the Commonwealth Mycological Institute, gave maximal growth when grown at $20^{\circ}$ for 30 days at $\mathrm{pH} 5 \cdot 8$ in a balanced solution containing: $4 \%(\mathrm{w} / \mathrm{v})$ glucose; $0.004 \mathrm{~m}-\mathrm{K}_{2} \mathrm{HPO}_{4} ; 0.002 \mathrm{~m}-\mathrm{MgSO}_{4} .7 \mathrm{H}_{2} \mathrm{O} ; 0.0375 \mathrm{~m}-\mathrm{NH}_{4} \mathrm{NO}_{3} ; \mathrm{Zn}$ and $\mathrm{Mn}$ at 2 p.p.m.; sufficient amounts of thiamine, pyridoxine, folic acid, nicotinic acid and ascorbic acid. Growth without these growth factors was negligible, but thiamine alone gave the greatest stimulation. Suggestions were made by Keitt and co-workers (Keitt, Palmiter \& Langford, 1938; Keitt \& Langford, 1941; Keitt, Langford \& Shax, 1943; Leben \& Keitt, 1948) that a genetic factor, or factors, in $\boldsymbol{V}$. inaequalis which was responsible for pathogenicity might be related to the nutritional requirements of the given pathogenic strain. In the present communication the results of a study of cultures from single ascopores are given.

\section{METHODS}

Eight cultures grown from eight ascospores isolated from a single ascus of Venturia inaequalis were kindly supplied by Professor G. W. Keitt, Pathology Department, Wisconsin University. They were numbered according to the position of the ascospore in the ascus, culture 1 having been derived from the apical spore and the others in order downwards. The following are known to be chromatid mates: 1,$2 ; 3,4 ; 5,6 ;$ and 7,8 . Single spore cultures were made

* Present address: The British Jute Trade Research Association, Dundee. 
from each of these, but unfortunately culture 7 died in transit. These cultures are designated C. 1, C. 2, .., C. 8. That part of the medium given above which contained the mineral salts and glucose only will be subsequently referred to as the basal medium. In each experiment $30 \mathrm{ml}$. volumes of basal medium were used in $150 \mathrm{ml}$. Erlenmeyer flasks with five replicates for each variation of medium; sterile phosphate solutions were added to the flasks after autoclaving. The inoculum for all experiments was prepared by adding $15 \mathrm{ml}$. sterile distilled water to a $6 \times \frac{3}{4}$ in. tube containing a well-grown culture on agar (30 days old). The surface of the agar was scratched with a sterile needle and $1 \mathrm{ml}$. of the resultant mycelial suspension was used as inoculum for each experimental flask of liquid medium. It was found by experience that the exact amount of the inoculum did not appreciably affect growth. Cultures

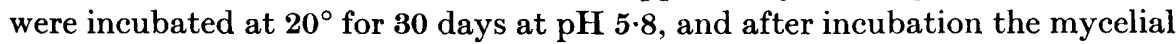
felts were harvested, dried at $95^{\circ}$ and weighed, amounts being expressed as mg. dry wt./flask.

Apple leaf decoctions were made by gently boiling $25 \mathrm{~g}$. air-dried apple leaves for $30 \mathrm{~min}$. in distilled water. After filtering, the amount of decoction was made up to one litre and incorporated into the basal medium so that each culture flask contained $5 \mathrm{ml}$. decoction. Decoctions were made from the following apple varieties: Laxton's Superb, Bramley's Seedling, Newton Wonder, James Grieve, Cox's Orange Pippin, Blenheim Orange Pippin, White Transparent, Wealthy.

\section{RESULTS}

\section{Effects of apple leaf decoctions on growth}

It is known that apple varieties respond differently to different strains of Venturia inaequalis. This observation may perhaps be correlated with differences in the food requirements which the apple is able to supply to the parasite. The growth of the monoascosporal cultures in the basal medium with the addition of decoctions of leaves from the different apple varieties was tested. The seven single cultures were each grown with each mixture of decoction + basal medium in five replicates; there was also a control with basal medium alone. The results are given in Table 1.

Table 1. Growth response of monoascosporal cultures of Venturia inaequalis to media containing leaf decoctions of different apple varieties

Results given as nearest mg. dry weight.

Basal medium + decoctions of

\begin{tabular}{|c|c|c|c|c|c|c|c|c|c|}
\hline Culture & $\begin{array}{c}\text { Laxton's } \\
\text { Superb }\end{array}$ & $\begin{array}{l}\text { Bramley's } \\
\text { Seedling }\end{array}$ & $\begin{array}{l}\text { Newton } \\
\text { Wonder }\end{array}$ & $\begin{array}{l}\text { James } \\
\text { Grieve }\end{array}$ & $\begin{array}{l}\text { Cox's } \\
\text { Orange } \\
\text { Pippin }\end{array}$ & $\begin{array}{c}\text { Blenheim } \\
\text { Orange } \\
\text { Pippin }\end{array}$ & $\begin{array}{l}\text { White } \\
\text { Trans- } \\
\text { parent }\end{array}$ & Wealthy & $\begin{array}{c}\text { Control } \\
\text { no } \\
\text { decoction }\end{array}$ \\
\hline C. 1 & 159 & 147 & 67 & 36 & 12 & 61 & 104 & 62 & 15 \\
\hline C. 2 & 95 & 68 & 55 & 32 & 38 & 80 & 34 & 39 & 11 \\
\hline C. 3 & 49 & 78 & 101 & 51 & 138 & 176 & 106 & 45 & 20 \\
\hline C. 4 & 38 & 44 & 46 & 44 & 63 & 62 & 43 & 43 & 16 \\
\hline C. 5 & 182 & 140 & 147 & 217 & 150 & 423 & 167 & 37 & 7 \\
\hline C. 6 & 74 & 98 & 182 & 155 & 134 & 258 & 125 & 62 & 9 \\
\hline C. 8 & 72 & 73 & 125 & 122 & 167 & 116 & 104 & 53 & 11 \\
\hline
\end{tabular}


With one exception it was seen that all growths with decoction were greater than the growths without decoction. Each culture varied in its amount of growth with each decoction, and with any one decoction the cultures varied in the amount of growth. Generally the faster growing cultures, which are C. 5, C. 6 and C. 8, gave greater mean weights than the slower growing cultures. Notable exceptions are seen in the growth of C. 1 with Cox's Orange Pippin and C. 3 with James Grieve and Wealthy decoctions. Except for C. 1 with Cox's Orange Pippin, C. 2 with James Grieve and White Transparent and C. 4 with Laxton's Superb decoctions, the growth of all cultures with Wealthy decoctions was poorer than with the others. C. 4 is a slow growing culture and its growth with decoction was generally lower than that of the other cultures. Johnstone (1931) found that leaf extracts derived from resistant varieties of apple were more toxic to Venturia inaequalis than extracts from susceptible varieties. Thus the presence of toxic substances in the leaves might account for the low growths of some of the cultures. This set of experiments indicated that the apple leaves contained substances stimulatory to the good growth of $V$. inaequalis on the basal medium used.

It was also noted that, in general, cultures C. 1, C. 3 and C. 5 gave greater growth than their corresponding chromatid mates. This result supports that of Keitt \& Langford (1941), who found that several apple varieties differed similarly in their resistance to the eight ascosporal cultures of a single ascus.

\section{The nutritional requirements of the monoascosporal cultures}

Because of the varying behaviour of the cultures to the different decoctions it became necessary to study the nutritional requirements of the seven cultures C. 1 to C. 8.

The effect of added growth factors and apple leaf decoctions. In this experiment the five growth factors known to stimulate an English strain of Venturia inaequalis were used with or without added leaf decoction. A preliminary experiment showed that these five growth factors either did not stimulate growth of the cultures C. 1 to C. 8 , or did so only to a limited extent; only cultures C. 2 and C. 3 showed a significant response to thiamine or folic acid. If any of the five growth factors tested was essential to the growth of the fungus in addition to those added in the decoction, addition of it to the basal medium + decoction should be reflected in an increased yield of growth. The growths of cultures C. 5, C. 6 and C. 8 did show a significant increase.

The effect of manganese and $\beta$-indolylacetic acid. Some claims have been made that $\beta$-indolylacetic acid, the natural growth hormone, increases the growth of fungi in cultures (Hawker, 1950). Epstein \& Lilleland (1942) found that apple leaves contained a high proportion of manganese, namely 81 p.p.m. of dry weight. It was possible that Venturia inaequalis required a much higher concentration of this metal than hitherto used in our cultures. The effect of 1 p.p.m. of $\beta$-indolylacetic acid and 80 p.p.m. manganese was tested with culture C. 5 with and without Bramley's Seedling decoction. The results showed that in the absence of apple leaf decoction neither $\beta$-indolylacetic acid nor manganese 
increased the growth of culture C. 5, but in the presence of decoction both of these substances increased the growth.

The effect of the nitrogen source. Experiments with the Commonwealth Mycological Institute strain of Venturia inaequalis CMI 24,006 showed that $\mathrm{NH}_{4} \mathrm{NO}_{3}$ in the basal medium was a better source of nitrogen than asparagine, provided that the five growth factors were also present. Palmiter (1934) found that the nitrogen source had a marked effect on the growth of $V$. inaequalis. Hence a series of experiments was made to test the effects of different nitrogen compounds on the monoascosporal cultures. The basal medium was used under the usual conditions, but the $\mathrm{NH}_{4} \mathrm{NO}_{3}$ in it was replaced in turn by $\mathrm{Ca}\left(\mathrm{NO}_{3}\right)_{2}$, $\mathrm{KNO}_{3},\left(\mathrm{NH}_{4}\right)_{2} \mathrm{SO}_{4}$, asparagine and Oxoid peptone in concentrations to give an amount of nitrogen equal to that in $0.0375 \mathrm{M}-\mathrm{NH}_{4} \mathrm{NO}_{3}$. Each nitrogen compound was tested in the presence or absence of Bramley's Seedling apple leaf decoction. The results are given in Table 2 . It has already been noted that

Table 2. The response of monoascosporal cultures of Venturia inaequalis to different nitrogen sources in the basal medium

\begin{tabular}{|c|c|c|c|c|c|c|c|c|c|c|c|c|}
\hline \multirow[b]{3}{*}{ Culture } & \multicolumn{12}{|c|}{$\begin{array}{l}\text { Results given as mean of five replicates to nearest mg. } \\
\text { Nitrogen source }\left(\equiv 0.0375 \mathrm{M}-\mathrm{NH}_{4} \mathrm{NO}_{3}\right)\end{array}$} \\
\hline & \multicolumn{2}{|c|}{$\mathrm{Ca}\left(\mathrm{NO}_{3}\right)_{2}$} & \multicolumn{2}{|c|}{$\mathrm{KNO}_{3}$} & \multicolumn{2}{|c|}{$\mathrm{NH}_{4} \mathrm{NO}_{3}$} & \multicolumn{2}{|c|}{$\left(\mathrm{NH}_{4}\right)_{2} \mathrm{SO}_{4}$} & \multicolumn{2}{|c|}{ Asparagine } & \multicolumn{2}{|c|}{$\begin{array}{l}\text { Oxoid } \\
\text { peptone }\end{array}$} \\
\hline & + & - & + & - & + & - & + & - & + & - & + & - \\
\hline C. 1 & 190 & 46 & 114 & 16 & 147 & 15 & 83 & 15 & 185 & 43 & 186 & 328 \\
\hline C. 2 & 168 & 9 & 46 & 9 & 68 & 11 & 66 & 4 & 67 & 24 & 63 & 39 \\
\hline C. 3 & 91 & 7 & 49 & 12 & 78 & 20 & 129 & 8 & 106 & 36 & 70 & 53 \\
\hline C. 4 & 54 & 2 & 43 & 5 & 44 & 16 & 75 & 9 & 62 & 23 & 79 & 36 \\
\hline C. 5 & 100 & 3 & 107 & 9 & 140 & 9 & 136 & 14 & 214 & 18 & 307 & 195 \\
\hline C. 6 & 90 & 11 & 77 & 6 & 98 & 9 & 145 & 17 & 118 & 14 & 305 & 120 \\
\hline C. 8 & 91 & 12 & 67 & 8 & 74 & 11 & 130 & 16 & 238 & 43 & 233 & 108 \\
\hline
\end{tabular}

$+=$ Bramley's Seedling apple leaf decoction present; $-=$ decoction absent.

apple leaf decoction seems to supply some factor essential for good growth of $V$. inaequalis. Table 2 shows that in the absence of the decoction variation in the inorganic nitrogen source had little effect except in the case of culture $\mathrm{C} .1$ with $\mathrm{Ca}\left(\mathrm{NO}_{3}\right)_{2}$. In the presence of decoction there was a great variation in the responses of the various cultures to the different inorganic nitrogen sources. For example, $\mathrm{Ca}\left(\mathrm{NO}_{3}\right)_{2}$ is the best source for C. 1 and C. $2, \mathrm{NH}_{4} \mathrm{NO}_{3}$ for C. 5 and $\left(\mathrm{NH}_{4}\right)_{2} \mathrm{SO}_{4}$ for C. 3, C. 4, C. 6 and C. 8. Many of these cultures fell into their chromatid pairs in their reaction to these compounds; the same nitrogen source produced the highest growth in each member of a chromatid pair. Table 2 shows that, in the absence of decoction, asparagine gave a better growth in more of the cultures than the inorganic sources. Oxoid peptone, however, in the absence of decoction gave as good growth as $\mathrm{NH}_{4} \mathrm{NO}_{3}$ did in the presence of decoction for cultures C. 1, C. 5, C. 6 and C. 8. The growth of culture C. 1 with Oxoid peptone was extraordinarily good, but this strain is fast growing, 
and its mycelial weight in one medium should only be compared with the corresponding weights in other media, rather than with weights of other strains. In the presence of apple decoction asparagine and Oxoid peptone were both good nitrogen sources for most of the cultures; peptone gave a very high weight of organism with some of the cultures, e.g. C. 5, C. 6 and C.8. It was concluded that the Oxoid peptone contained material which stimulated the growth of $V$. inaequalis and which was possibly present in the apple leaf decoctions.

Determination of the unknown stimulatory material in apple leaf decoction. A quantity of crushed air-dried Bramley's Seedling apple leaves equivalent to $25 \mathrm{~g}$. leaves/l. medium were extracted in a Soxhlet apparatus with ether for $\mathbf{3 0} \mathrm{hr}$. The powdered leaves were dried, a decoction prepared and added to the basal medium. This mixture was tested with all the monoascosporal cultures (five replicates) and gave mycelial weights as follows: C. 1..C. 8, 172, 65, 57, $40,202,115$ and $83 \mathrm{mg}$. respectively. With all the cultures on this mixture, except C. 3, the results were as good as, or better than, those obtained when a decoction of untreated leaves and $\mathrm{NH}_{4} \mathrm{NO}_{3}$ in the medium were used. The material in the ether extract added to the basal medium caused no significant increase in growth of the cultures tested. The material in the leaves which increased growth seemed to be water soluble and probably ether insoluble.

A quantity of Bramley's Seedling apple leaves equivalent to $25 \mathrm{~g}$. leaves/l. medium were extracted in cold water in the dark for 3 days and filtered. Of this filtrate one part was tested with culture C. 1 with and without basal medium and gave weights of 174 and $17 \mathrm{mg}$. respectively. The other part of this filtrate was added to a volume of methylated ether, shaken and separated. The water separation was then steamed and tested with culture C. 1 with and without addition of basal medium; the weights of organism were 167 and $16 \mathrm{mg}$. respectively. The methylated ether separation was evaporated to dryness, the residue taken up with water and tested with culture C. 1 with and without addition of basal medium; the weights of organism were 34 and $2 \mathrm{mg}$. respectively.

Thus the growths produced by the cold water extract and the water fraction after ether extraction were about five times that produced by the ether fraction, and they were also slightly greater than the growth produced by the hot-water extract in the previous experiment. Thus the growth stimulatory substances in apple leaves are soluble in cold water and are possibly partially destroyed by heating. The flasks with each nutrient minus the basal medium showed that any carbohydrates and salts present in the decoctions did not influence the dry weight to any appreciable extent; with the ether fraction growth was negligible.

Smith \& Jones (1948) determined that the non-volatile compounds insoluble in ether from such leaf extracts as above are carbohydrates, polyhydroxy compounds, salts of organic bases with mineral acids, metallic salts, compounds with sulphonic acid group and amino acids. Our experiments showed that the stimulatory substances present in apple leaves are not carbohydrates and salts. Moreover, carbohydrates are not present in Oxoid peptone, and we have shown that this peptone contains the stimulatory substances. Leben \& Keitt (1948) 
found that the growth of Venturia inaequalis on a defined medium was greatly increased by the addition of extracts of malt, liver, yeast or dead apple leaves. They also found that malt extract ash and minor elements did not increase growth, and concluded that the stimulatory substances must be organic materials such as vitamins. Amino acids and various vitamins are recognized growth factors for many fungi and bacteria. The $\mathbf{B}$ vitamins are ether insoluble and water soluble, and as chemicals some of them come into the third group mentioned above. Thus it would seem that amino acids, most of which are readily soluble in water, and possibly some vitamins of the $\mathbf{B}$ group, are the substances in apple leaves which stimulate the growth of the apple scab fungus.

Leben \& Keitt (1948) found thiamine was the only growth factor which stimulated Venturia inaequalis; the effect was varied with different cultures. It was shown (Fothergill \& Ashcroft, 1955) that a strain of $V$. inaequalis was stimulated in growth by thiamine, folic acid, pyridoxine, nicotinic acid and ascorbic acid. Thiamine alone gave the greatest stimulation. Earlier we showed that the growth of some of the cultures was stimulated by addition of a mixture of these five vitamins + leaf decoction. The results were variable, and it was difficult to select any one growth factor as the one giving the greatest effect; thiamine may have been stimulatory. The effect of thiamine alone and with leaf decoction was next tried on the monoascosporal cultures and on the Commonwealth Mycological Institute strain (C.M.I.). The results are given in Table 3.

Table 3. The response of monoascosporal cultures of Venturia inaequalis and C.M.I. strain to thiamine and leaf decoction

Results given as mean of five replicates to nearest $\mathrm{mg}$. Control: average value for basal medium alone $=13 \mathrm{mg}$.

\begin{tabular}{|cc} 
Culture & $\begin{array}{c}\text { Basal medium }+ \\
\text { thiamine }\end{array}$ \\
C. 1 & 118 \\
C. 2 & 30 \\
C. 3 & 69 \\
C. 4 & 31 \\
C. 5 & 62 \\
C. 6 & $\mathbf{5 0}$ \\
C. 8 & $\mathbf{5 4}$ \\
C.M.I. & $\mathbf{3 5}$
\end{tabular}

Basal medium +
decoction
147
65
68
64
162
156
196
120
Basal medium + thiamine + decoction 222 69 70 63 172 203 200 160

These results showed that the addition of thiamine to the basal medium greatly increased the growth of all the cultures but to a varying extent. In the previous experiment with five growth factors the effect of the other four possibly masked and interfered with the action of thiamine. In this experiment the addition of thiamine to the medium containing decoction produced a greater growth than the medium with decoction but without the growth factor, varying in amount with the culture used. Strains C. 3 and C. 4 were not affected. In most of the cultures with the decoction + thiamine the growth was as great as, or greater than, the weight obtained in the previous experiment 
when five growth factors together were added. Thus it seems that thiamine is the chief vitamin which stimulates the growth of the monoascosporal cultures and the remaining four (i.e. pyridoxine, folic acid, nicotinic acid and ascorbic acid) have only a slight effect.

\section{The effect of amino acids on growth of Venturia inaequalis}

In the experiments described below the amino acids present in apple leaf decoction were determined by paper chromatography, and then the effects of these compounds with or without thiamine were tried on the cultures. The technique of paper partition chromatography as used by Consden, Gordon \& Martin (1944) was used with sheets of Whatman no. 1 filter-paper, size $18 \frac{1}{4} \times$ $22 \frac{1}{2}$ in. One- or two-dimensional chromatograms were made with phenol/water and butanol/acetic acid mixture as solvents. The results are aggregated in Table 4.

\begin{tabular}{lcccccc}
\multicolumn{7}{c}{ Table 4. Amino acid content of leaves of different apple varieties } \\
\multicolumn{1}{c}{ Laxton's } & Bramley's & James & Newton & Blenheim & Cox's \\
Amino acid & Superb & Seedling & Grieve & Wonder & Orange & Pippin \\
Aspartic acid & + & + & + & + & + & + \\
Glutamic acid & + & $\mathbf{P}$ & - & + & $\mathbf{P}$ & $\mathbf{P}$ \\
Serine & + & + & + & + & + & + \\
Asparagine & + & + & - & - & - & - \\
Alanine & + & + & + & + & + & + \\
Valine & + & + & + & + & + & + \\
Phenylalanine & + & + & + & - & - & - \\
Isoleucine & + & $\mathbf{P}$ & - & - & - & - \\
Glycine & + & $\mathbf{P}$ & + & - & $\mathbf{P}$ & - \\
Glutamine & $\mathbf{P}$ & $\mathbf{P}$ & $\mathbf{P}$ & - & - & -
\end{tabular}

$+=$ amino acid present; $-=$ acid absent; $\mathbf{P}=$ probably present.

Aspartic acid, serine, alanine and valine were detected in the decoctions from the leaves of all the apple varieties analysed. Glutamic acid, phenylalanine, glycine, isoleucine, asparagine and glutamine were detected only in some varieties. Either leucine or isoleucine was present in Laxton's Superb and Bramley's Seedling leaves. Leucine and isoleucine are difficult to separate in chromatograms, but Hulme \& Arthrington (1950) stated that isoleucine and not leucine was present in Bramley's Seedling fruit.

A series of experiments was set up using the amino acids found in the apple leaf decoction and the monoascosporal cultures. A test experiment indicated that most information would be obtained by adding the various amino acids separately to the medium in the presence and absence of thiamine, for some amino acids seemed to stimulate growth and others to inhibit it. Various amino acids at $200 \mathrm{mg}$./l. were tested separately (in quadruplicate).

The results of this set of experiments showed that, except for strain C. 3, where an increased growth was shown, aspartic acid did not affect the growth of the cultures of Venturia inaequalis in the absence of thiamine, but in its presence the growth of C. 1, C. 2, C. 5, C. 6 and C. 8 was decreased in spite of 
the fact that when tested in decoction asparagine increased growth. Glutamic acid did not stimulate the growth of any of the cultures either in the presence or absence of thiamine. Serine increased the growth of C. 6 and C. 8 in the presence and absence of thiamine, and C. 3 only in the presence of the growth factor. All cultures except C. 1 showed an increase in growth with alanine in the presence of thiamine, while C. 5, C. 6 and C. 8 showed increase also in its absence. In the presence of thiamine, phenylalanine increased the growth of C. 3, C. 4, C. 6 and C. 8, but in its absence C. 1, C. 4, C. 6 and C. 8 were stimulated. Isoleucine increased growth of C. 1 and C. 6 and C. 8 only slightly in the absence of thiamine and C. 1, C. 3, C. 5, C. 6 and C. 8 in its presence. Glycine stimulated all cultures in the presence of this growth factor, but only C. 1, C. 5, C. 6 and C. 8 in its absence. In the absence of thiamine valine increased the growth of all cultures to some extent and in its presence that of C. 1, C. 2, C. 5, C. 6 and C. 8. Finally glutamine increased the growth of C. 1, C. 2, C. 5, C. 6 and C. 8 in the presence and absence of thiamine.

\section{DISCUSSION}

The experiment with leaf decoctions of various named varieties of apple indicates that apple leaves contain substances which are needed as nutrients for the growth of Venturia inaequalis on a medium containing: $4 \%(\mathrm{w} / \mathrm{v})$ glucose; $0.004 \mathrm{M}-\mathrm{K}_{2} \mathrm{PO}_{4} ; 0.002 \mathrm{M}-\mathrm{MgSO}_{4} .7 \mathrm{H}_{2} \mathrm{O} ; 0.0375 \mathrm{M}-\mathrm{NH}_{4} \mathrm{NO}_{3} ; \mathrm{Zn}$ and $\mathrm{Mn}$ at 2 p.p.m. By using cultures derived from the products of a single ascus, which normally behave alike in genetic or chromatid pairs, it was found that in general one set of genetic mates responded differently in growth on the defined medium from the other set. Similarly, in general the cultures differed in their ability to use different nitrogen sources. The chromatid mates of each genetic pair behaved similarly with regard to the nitrogen compound in the presence of apple leaf decoction in the basal medium. In the absence of apple leaf decoction Oxoid peptone and, to a lesser extent, asparagine are good sources of nitrogen. Further experiments showed that in the presence of thiamine the amino acids isoleucine, glutamine, serine and phenylalanine have a differential effect on the growth of the cultures. Thus, although the results are not conclusive, they indicate that nutrition may be genetically controlled in a way which is similar to the inheritance of pathogenicity of $V$. inaequalis (Keitt \& Langford, 1941).

The authors would like to thank Professor G. W. Keitt of Wisconsin University who kindly supplied the monoascosporal cultures.

\section{REFERENCES}

Consden, R., Gordon, A. H. \& Martin, A. J. P. (1944). Quantitative analysis of proteins : a partition chromatographic method using paper. Biochem. J. 38, 224.

Epstein, E. \& Lilleland, O. (1942). Preliminary study of the manganese content of leaves of some deciduous fruit trees. Proc. Amer. Soc. hort. Sci. 41, 11.

Fothergill, P. G. \& Ashcroft, R. (1955). The nutritional requirements of Venturia inaequalis. J. gen. Microbiol. 12, 387. 
Hawker, L. (1950). Physiology of Fungi, p. 93. London: University of London Press.

Hulme, A. C. \& Arthrington, W. (1950). Amino acids of apple fruit. Nature, Lond. 165, 716.

Johnstone, K. H. (1931). Observations on the varietal resistance of the apple scab (Venturia inaequalis Aderh.) with special reference to its physiological aspects. J. Pomol. 9, 30, 195.

Keitt, G. W., Palmiter, D. H. \& Langford, M. H. (1938). Heterothallism and segregation for pathogenicity in Venturia inaequalis. Phytopathology, $28,12$.

Keitt, G. W. \& Langford, M. H. (1941). Venturia inaequalis (Cke.), Wint., 1. A groundwork for genetic studies. Amer. J. Bot. 28, 805.

Keitr, G. W., LANGford, M. H. \& Shax, J. R. (1943). Venturia inaequalis. 2. Genetic studies on pathogenicity and certain mutant characters. Amer. J. Bot. 35, 337.

Leben, C. C. \& KeITT, G. W. (1948). Venturia inaequalis, 5. The influence of carbon and nitrogen sources and vitamins on growth in vitro. Amer. J. Bot. 35, 337.

Palmiter, D. H. (1934). Variability in monoconidial cultures of Venturia inaequalis. Phytopathology, 24, 22.

Sмiтh, F. J. \& Jones, E. (1948). A Scheme of Qualitative Organic Analysis. London: Blackie and Son.

(Received 21 January 1955) 